\title{
Análise das vantagens e desvantagens das marcas próprias do atacado para os clientes varejistas
}

\author{
Éderson Luiz Piato ${ }^{\text {a* }}$, Andrea Lago da Silva ${ }^{\mathrm{b}}$, Verônica Angélica Freitas de Paula ${ }^{\mathrm{c}}$ \\ a*piato@ufscar.br, UFSCar, Brasil \\ bdeialago@ufscar.br, UFSCar, Brasil \\ 'veronica@fagen.ufu.br, UFU, Brasil
}

\begin{abstract}
Resumo
0 objetivo deste artigo é identificar e discutir as principais vantagens e desvantagens para os pequenos e médios varejistas supermercadistas na comercialização de produtos de marcas próprias do atacadista distribuidor. A partir de um estudo qualitativo-exploratório, no qual foram realizadas entrevistas semiestruturadas junto a 15 varejistas supermercadistas, observou-se que muitas vantagens e desvantagens relacionadas pela literatura com base em varejistas de grande porte e atacadistas se assemelham àquelas apontadas pelos varejistas. Contudo, os varejistas apontam dificuldades inerentes ao processo de comercialização que nenhum outro agente distribuidor apresenta. Verificou-se que apenas os varejistas associados à rede do atacadista se beneficiam das principais vantagens das marcas próprias, pois os varejistas independentes possuem restrições quanto ao vínculo das marcas com as lojas e veem como principal vantagem a obtenção de margens de lucro mais elevadas. Desvantagens/dificuldades na comercialização de marcas próprias também são apontadas por clientes varejistas.
\end{abstract}

Palavras-chave

Marcas próprias. Atacado distribuidor. Varejo supermercadista.

\section{Introdução}

0 crescimento do setor atacadista distribuidor nos últimos dez anos esteve relacionado ao crescimento do pequeno e médio varejo supermercadista. Em 2008, o varejo nacional obteve seu melhor desempenho, registrando crescimento no faturamento das vendas reais de 10,5\% (HILÁRIO, 2009). Esse desempenho se deve ao crescimento de todos os formatos de varejo, especialmente dos supermercados médios, com crescimento de $11,6 \%$, e do pequeno varejo, que cresceu 6,5\% (ELO1, 2009). Em 2010, os supermercados médios também foram os que mais cresceram $(9,7 \%)$ e os pequenos supermercados cresceram 6\% (ELOl, 2011).

0 setor atacadista distribuidor foi um dos indutores desse crescimento pois, além de ser importante fornecedor desse mercado (ELOl, 2009), também contribuiu para o melhor desempenho competitivo desses clientes. Assim como na Europa e EUA, o setor atacadista brasileiro também adotou nova postura estratégica e passou a se envolver mais com questões mercadológicas (ALCÂNTARA, 1997), principalmente relacionadas ao desenvolvimento de marcas (PIATO, 2006). 0 atacado brasileiro também descobriu a importância da utilização da estratégia de marcas próprias - "[...] marcas desenvolvidas e vendidas com exclusividade por varejistas ou atacadistas." (PARENTE, 2000, p. 194).

0 Brasil configura um mercado em desenvolvimento no qual a participação das marcas próprias é de apenas 6\% em volume (ASSOCIAÇÃO..., 2011); de 893 empresas pesquisadas no país, 163 possuem marcas próprias, sendo 106 varejistas supermercadistas (65\%), 36 atacadistas $(22,1 \%)$ e 21 farmácias $(12,9 \%)$ (LUKIANOCENKO, 2010). As marcas próprias se apresentam como oportunidade do atacadista ampliar seu mix de produtos e serviços, oferecendo exclusividade e menores preços, o que é um diferencial competitivo importante, principalmente para os seus clientes - o pequeno e o médio varejista (PUERTA, 2006). 
A estratégia de marca própria como tópico regular de estudo alcançou dimensões importantes a partir dos anos 1990. Entretanto, as proposições teóricas encontradas na literatura estão baseadas no setor varejista de grande porte. Especificamente, baseiam-se na análise da disputa entre marcas próprias do varejo e marcas de fabricante $(\mathrm{HOCH}$; BANERJl, 1993; HOCH, 1996; PARKER; KIM, 1997; DHAR; HOCH, 1997; DHAR et al., 2001; VERHOEF; NIJSSEN; SLOOT, 2002; DAVIES; BRITO, 2004; STEINER, 2004; KOTLER; KELLER, 2006; KUMAR; STEENKAMP, 2008); na avaliação das atitudes e preferências dos consumidores comparando marcas nacionais tradicionais com as marcas próprias do varejo (RICHARDSON, 1997; BATRA; SINHA, 2000; GARRETSON et al., 2002), na mensuração da imagem (AlLAWADI; KELLER, 2004; VAHIE; PASWAN, 2006; PEETERS et al., 2006); e na fidelidade (CORSTJENS; LAL, 2000; DATTA, 2003; BELL; CUTHBERTSON; KOSKINEN, 2005; HUANG; HUDDLESTON, 2009) do consumidor em relação à marca e à loja do varejo.

Artigos, teses e dissertações focalizam em maior parte as perspectivas do varejo supermercadista de grande porte e do consumidor final de marca própria. Como exceções, os estudos de Oliver (2001), Toillier (2003), Oubiña, Rubio e Yagüe (2006), Tarziján (2007), Gómez e Rubio (2008), Gómez e Benito (2008) e Yokoyama (2010) focalizam a perspectiva dos fabricantes de marcas próprias; e o de Piato (2006), a perspectiva dos atacadistas. Embora seja comum encontrar argumentos generalistas que definam teoricamente a estratégia de marca própria como uma atividade de varejistas e atacadistas, na prática as pesquisas empíricas estão baseadas em empresas varejistas supermercadistas de grande porte.

As marcas próprias como tendência presente no atacado e, consequentemente, no pequeno e médio varejos, é um campo de conhecimento pouco explorado pelo meio acadêmico nacional e internacional. A escassez de estudos promove questionamentos sobre o contexto estratégico das marcas próprias, principalmente em relação às vantagens e desvantagens na comercialização desses produtos/marcas para pequenos e médios varejistas, uma vez que a estratégia é desenvolvida pelo atacadista distribuidor. Portanto, a compreensão da perspectiva dos varejistas inseridos nesse contexto constitui razão essencial para fundamentar discussões sobre o gerenciamento de marcas próprias nos canais de distribuição.

Este artigo procura identificar e discutir as principais vantagens e desvantagens, para os pequenos e médios varejistas supermercadistas, da comercialização de produtos de marcas próprias do atacado distribuidor. Inicialmente é apresentado o referencial teórico, com considerações sobre marcas próprias, suas vantagens e desvantagens. Em seguida são apresentados o procedimento metodológico e os resultados do estudo qualitativo-exploratório sob a perspectiva de pequenos e médios varejistas. Por fim são apresentadas as conclusões e sugestões para pesquisas futuras.

\section{Referencial teórico}

\subsection{Marcas próprias}

A marca própria, segundo Churchill Junior e Peter (2000, p. 246), baseia-se na "marca de propriedade e uso de um atacadista ou varejista". A marca própria é

[...] aquela que é possuída ou controlada, por meio de direitos de contrato, por uma empresa varejista, por um grupo filiado de varejistas ou por uma organização compradora. (STERN; EL-ANSARY; COUGHLAN, 1996, p. 326).

Embora a fabricação fique a cargo da indústria, os direitos de propriedade e uso dos produtos são transferidos para os revendedores (atacadistas e ou varejistas) (BOWERSOX; COOPER, 1992), que se encarregam de gerenciar o produto com sua própria marca, vendendo-os exclusivamente em seus estabelecimentos (PARENTE, 2000; OLIVEIRA, 2005).

As marcas próprias surgiram no Brasil na década de 1970, implantadas por iniciativa de redes multinacionais como Carrefour e Makro e redes nacionais como o Grupo Pão de Açúcar. As marcas próprias surgiram como

evolução das marcas genéricas, também conhecidas como "marcas do dono da loja" que atualmente ainda podem ser encontradas em mercearias tradicionais $\mathrm{e}$ lojas de vizinhança (TAVARES, 1998; OLIVEIRA, 2005). Os produtos de marca genérica são versões sem marca de produtos comuns (commodities), comercializados em embalagens simples e que perderam sua popularidade por possuírem baixa qualidade (CHURCHILL JUNIOR; PETER, 2000; BERKOWITZ et al., 2003).

Atualmente, os distribuidores passaram a investir em marcas mais elaboradas, com embalagens padronizadas e ênfase na qualidade, próximas das marcas líderes de mercado (AAKER, 1998; STEINER, 2004). Segundo Conn (2005), os clientes gradativamente têm aceitado a idéia de os distribuidores desenvolverem marcas premium, exclusivas e de qualidade superior e que não são necessariamente mais baratas que as marcas de fabricantes. Esse fato se tornou o principal elemento justificador do sucesso das marcas próprias (BURT, 2000). 


\subsection{Vantagens e desvantagens da comercialização de marcas próprias}

\section{a) Vantagens}

Os distribuidores que comercializam marcas próprias vislumbram nessa estratégia uma série de vantagens. As marcas próprias possuem margem de lucro mais alta por unidade do que as marcas de fabricantes, apesar de terem preços tipicamente menores para o consumidor final $(\mathrm{HOCH}$; BANERJl, 1993; COUGHLAN et al., 2002; GARRETSON et al., 2002). Em geral, as marcas próprias do varejo possuem margens de lucro próximas a 10\% (McGOLDRICK, 2005). No Brasil, os atacadistas trabalham, em média, com margens de lucro em torno de 12\% a 13\% (PIATO, 2006). Isso é possível porque os distribuidores buscam fabricantes com excesso de capacidade produtiva ou que possuam marcas pouco expressivas no mercado (BOWERSOX; COOPER, 1992) para produzirem suas marcas próprias a custos mais baixos. Com melhores margens, os distribuidores aumentam o portfólio de produtos de sua marca (GARRETSON et al., 2002).

Além disso, os varejistas consideram que os custos com pesquisa e desenvolvimento, propaganda, promoção de vendas e distribuição (que são de responsabilidade do distribuidor) também são mais baixos para as marcas próprias (KOTLER; KELLER, 2006). Como consequência, o distribuidor pode cobrar um preço menor pelos produtos - em média, entre $15 \%$ e $20 \%$ mais baixo que o das marcas de fabricantes (PAULA, 2008).

Os distribuidores também utilizam as marcas próprias como forma de reduzir a dependência dos produtos de marcas tradicionais. Geralmente, as marcas tradicionais são essenciais para varejistas e atacadistas, pois elas geram interesse e expectativas nos clientes (KELLER; MACHADO, 2006) e, muitas vezes, os mobilizam até o ponto de venda. Contudo, essas marcas oferecem margens de lucro mais baixas, direcionando a expectativa de retorno para o volume de vendas, o que não garante competitividade aos distribuidores.

0 confronto entre marcas de fabricantes e marcas próprias proporciona outra vantagem ao varejo, que estrategicamente utiliza as marcas próprias para diminuir o espaço disponível para as marcas de fabricantes (GARRETSON et al., 2002). 0 domínio do espaço no ponto de venda é razão muito significativa para explicar essa vantagem. Atualmente, é comum o varejista cobrar dos fabricantes de marcas nacionais taxas de utilização de determinados espaços na loja (KOTLER; KELLER, 2006). Dependendo do objetivo do varejista (LAAKSONEN; REYNOLDS, 1994), a marca própria pode possuir espaço privilegiado e ficar mais exposta ao cliente.
Para Hoch e Banerji (1993), Hoch (1996), Dhar e Hoch, (1997), Batra e Sinha (2000), Dhar et al. (2001) e Garretson et al. (2002), os varejistas são mais eficazes na disputa por determinados mercados alvo mediante o domínio do ponto de venda. Contudo, é importante destacar que a falta de domínio do ponto de venda é uma dificuldade inerente dos atacadistas distribuidores, que precisam manter relacionamento mais estreito e colaborativo com seus clientes varejistas para alinhar o foco no atendimento às necessidades dos clientes da loja.

Nesse sentido, os varejistas estão usando as marcas próprias como forma de diferenciação (CORSTJENS; LAL, 2000; DHAR et al., 2001; SULLIVAN; ADCOCK, 2002; McGOLDRICK, 2005; OLIVEIRA, 2005), oferecendo "exclusividade" aos seus clientes através do desenvolvimento de marcas que só podem ser encontradas em sua loja. Isso possibilita a redução da amplitude da competição por preços, representando vantagem competitiva para atacadistas e varejistas. Com isso, eles atraem e mantêm um grupo de clientes fiéis e lucrativos, além de melhorar o controle de suas ações de marketing (DATTA, 2003; HUANG; HUDDLESTON, 2009).

0 desenvolvimento de marcas com valor agregado que atendam às necessidades dos clientes permite ao varejo construir uma identidade de marca vinculada à imagem que o cliente possui da loja (BELL; CUTHBERTSON; KOSKINEN, 2005; KELLER; MACHADO, 2006). Tradicionalmente, as marcas de fabricante ajudaram o varejista a criar uma imagem positiva junto aos clientes (AlLAWADI; KELLER, 2004). A credibilidade transmitida por meio da imagem proporciona o aumento da fidelidade dos clientes que se identificam com a loja (CORSTJENS; LAL, 2000; DHAR et al., 2001; BALTAS, 2003; McGOLDRICK, 2005). Para os atacadistas as marcas próprias proporcionam a oportunidade de fidelização de clientes por meio da satisfação das necessidades de abastecimento e a oferta de serviços que agregam valor (PIATO, 2006). Assim, a vinculação da marca própria à imagem que o cliente varejista possui do atacadista pode estimular a lealdade e conferir maior credibilidade à marca.

\section{b) Desvantagens}

Embora existam muitas vantagens, os distribuidores também incorrem em algumas desvantagens/ dificuldades que, em um cenário pessimista, podem desencorajar a comercialização de marcas próprias. Como principal desvantagem pode-se apontar o aumento excessivo das despesas com estoques. Nesse sentido, alguns atacadistas brasileiros minimizam essa desvantagem firmando com o fabricante da marca própria um acordo de fornecimento que estabelece, entre outros aspectos, que não deverá haver excedente em estoque além do nível determinado pelo atacadista. 
Assim, os atacadistas exercem maior controle sobre os níveis de produção e eventuais excessos podem ser escoados com maior facilidade devido ao volume de suas transações (PIATO; PAULA; SILVA, 2011).

A utilização de marcas próprias também requer que os distribuidores realizem investimentos em design e teste de produtos, embalagens, estoques, espaço nas gôndolas, displays promocionais e propaganda. Assim, a função de desenvolvimento e gestão da marca (embalagem e comunicação) e a coordenação das fontes de suprimentos, funções tradicionalmente desempenhadas pelos fabricantes, agora ficam a cargo do distribuidor $(\mathrm{HOCH}$; BANERJl, 1993; McGOLDRICK, 2005). Além disso, os distribuidores passam a necessitar de estrutura capaz de especificar e testar as características dos produtos para conferir às marcas próprias a qualidade exigida pelos clientes (McGOLDRICK, 2005). Esses investimentos aumentam o risco assumido pelo distribuidor.

As mudanças ocorridas nas empresas que possuem marcas próprias podem representar uma ameaça estratégica na medida em que as marcas próprias começam a se mover para um status de marca de fabricante (HALSTEAD; WARD, 1995). A incorporação de muitas funções pelo distribuidor pode tornar a estratégia não mais desejável. Além disso, quando a oferta de marca própria excede certo percentual da linha de produtos, a variedade do varejista pode ser percebida pelo cliente como limitada ou monótona (PARENTE, 2000).

Outrossim, é importante salientar que a imagem do varejo é mais vulnerável devido à amplitude de categorias de produtos/marcas gerenciadas em uma loja (incluindo marcas próprias e de fabricantes). Problemas ocorridos com determinados produtos ou serviços, como queda na qualidade dos produtos, gerenciamento inadequado das categorias, deficiência no atendimento aos clientes, podem afetar a imagem global da loja e consequentemente, das marcas próprias (SOUZA; NEMER, 1993).

Outros fatores como o risco oferecido por produtos alimentícios passiveis de contaminarem-se e que geralmente possuem vida de prateleira inferior a 30 dias (produtos refrigerados, por exemplo) e o risco associado ao possível rompimento do acordo de fornecimento, que dificulta a manutenção do nível de qualidade dos produtos e compromete 0 abastecimento (SULLIVAN; ADCOCK, 2002), podem apresentar riscos mais graves para a imagem do varejista. Consequentemente, os distribuidores correm o risco de associar marcas próprias a produtos e situações (como a falta de produto) que inibem atitudes favoráveis dos clientes à compra.

De acordo com Hoch e Banerji (1993), Souza e Nemer (1993), Dhar e Hoch (1997), as vantagens e desvantagens para os distribuidores na comercialização de marcas próprias podem variar em função da categoria de produto, das características do mercado, da concorrência e do tipo de relacionamento que o distribuidor possui com seus fornecedores.

\section{Procedimento metodológico}

A pesquisa realizada para este artigo foi qualitativa com propósito exploratório, pois produziu resultados não provenientes de procedimentos estatísticos (STRAUSS; CORBIN, 1998; RICHARDSON et al., 1999). 0 objetivo foi explorar diferentes opiniões e representações do tema abordado a fim de identificar perspectivas (visões) que revelassem a dinâmica da problemática em análise (BAUER; GASKELL, 2002). Esta pesquisa explorou de forma específica a perspectiva de pequenos e médios varejistas em relação às vantagens e desvantagens da comercialização de marcas próprias. Ressalta-se que essa perspectiva era, até então, desconhecida em relação ao objeto de estudo.

As unidades de análise (agentes investigados) são os pequenos e médios varejistas que comercializam marcas próprias de atacadistas distribuidores. Para caracterizar estruturalmente esses pequenos e médios varejistas utilizou-se a classificação de Parente (2000) e os critérios de classificação do ranking ABRAS 2010 (HILÁR10, 2010). A Tabela 1 apresenta as características dos formatos estudados nesta pesquisa. Ressalta-se que esses formatos de varejo podem atuar de forma totalmente independente ou, então, em sistemas de marketing verticais caracterizados por cadeias ou redes de varejistas organizadas por um atacadista.

As unidades de análise foram selecionadas intencionalmente a partir de procedimentos definidos pelos pesquisadores. Primeiro foram realizados contatos junto a dois atacadistas distribuidores A e B cujos nomes não serão divulgados nesta pesquisa, os quais comercializam em torno de 800 e 300 itens de marcas próprias, respectivamente. 0 objetivo do contato foi

Tabela 1. Formatos de varejo abordados na pesquisa.

\begin{tabular}{lcccl}
\multicolumn{1}{c}{ Formatos de varejo } & Área de vendas $\left(\mathrm{m}^{2}\right)$ & $\mathrm{N}^{\circ}$ médio de itens & $\mathrm{N}^{\circ}$ de check-outs & \multicolumn{1}{c}{ Designação } \\
\hline Minimercado & Até 250 & 2.177 & $1-2$ & Pequeno varejo \\
Supermercado compacto & $251-1.000$ & 7.608 & $3-6$ & Pequeno varejo (de vizinhança) \\
Supermercado convencional & $1001-2500$ & 14.566 & $7-20$ & Médio varejo \\
\hline
\end{tabular}

Fonte: adaptado de Parente (2000) e Hilário (2010). 
solicitar aos atacadistas informações importantes, entre elas: a quantidade de clientes que efetivamente compram marcas próprias, assim como o contato desses clientes. Apenas o atacadista A (o maior do país no egmento) concordou em colaborar com a pesquisa.

Foi possivel filtrar no banco de dados do atacadista A apenas os varejistas que adquiriram marcas próprias no período de setembro de 2009 a setembro de 2010 . Esses clientes estavam concentrados nos estados de SP e MG. Com base nessas informações e em estudo realizado pela ACNielsen (ASSOCIAÇÃO..., 2010), foram pré-selecionados os 20 primeiros clientes varejistas supermercadistas do estado de São Paulo, sob o critério maior volume de compra de marcas próprias, dos quais dez eram independentes e os outros dez, associados à rede de varejo coordenada pelo atacadista. Da mesma forma foram selecionados os 20 primeiros clientes varejistas do estado de Minas Gerais, sob os mesmos critérios, dos quais dez eram independentes e dez eram associados à mesma rede.

Após a pré-seleção das unidades de análise, foi estruturado o roteiro de entrevista, pré-testado em um estudo piloto realizado no inicio do mês de outubro de 2010 por meio de entrevistas realizadas com dois gerentes/proprietários de estabelecimentos varejistas de Itajubá, MG, e Pouso Alegre, MG. A escolha desses clientes foi acidental e por conveniência, uma vez que ambos varejistas atendiam os critérios da pesquisa. Após adequação do roteiro, os 40 clientes pré-selecionados foram contatados por telefone, em ordem decrescente. Na prática, foram efetuadas 15 entrevistas semiestruturadas com estabelecimentos de diferentes cidades de São Paulo e Minas Gerais no período de outubro a dezembro de 2010.

Para análise dos dados foram parcialmente utilizados os procedimentos estruturais da análise de conteúdo proposta por Bardin (2004). Destaca-se que esta pesquisa não realizou uma análise de conteúdo tradicional, mas foi utilizado um procedimento semelhante, diferindo apenas na forma de relacionar e interpretar os dados. Essa adequação foi necessária para o alcance do objetivo da pesquisa. Os procedimentos adotados na análise dos dados com base em Bardin (2004) consistiram nas seguintes fases: realização de pré-análise; exploração do material; tratamento e interpretação dos resultados.

A pré-análise dos dados consistiu na transcrição das entrevistas (MAXWELL, 1996), cujas gravações (áudio) foram conservadas. A exploração do material consistiu nas operações de codificação, categorização (BARDIN, 2004) e triangulação das fontes de dados (MAXWELL, 1996; DENZIN; LINCOLN, 1998), sob a lógica comparativa (MASON, 2006). Na fase de tratamento e interpretação dos resultados foram sintetizadas as entrevistas comparativamente aos dados secundários. Após a interpretação da perspectiva dos clientes varejistas em relação às vantagens e desvantagens das marcas próprias em seu contexto e com o apoio do referencial teórico, foi realizado um esquema comparativo entre as perspectivas dos varejistas de grande porte, dos atacadistas distribuidores e dos clientes varejistas.

É importante destacar que a metodologia da pesquisa apresenta algumas limitações inerentes à natureza do próprio método. Por se tratar de pesquisa de campo exploratória, com abordagem qualitativa, as análises e considerações feitas neste artigo estão baseadas no contexto específico das empresas estudadas e, portanto, se limitam a essas empresas. Assim, generalizações devem ser contidas ou realizadas com cautela, evitando-se possíveis distorções. Em estudos qualitativos, a conduta humana é instável e as particularidades do contexto analisado impedem as generalizações (RICHARDSON et al., 1999). Essa preocupação com o contexto, habitual na pesquisa qualitativa, explica sua incapacidade de suportar a generalização dos resultados (STRAUSS; CORBIN, 1998).

\section{Análise e discussão dos resultados}

\subsection{Caracterização do perfil das empresas varejistas estudadas}

Para caracterizar os varejistas que participaram desta pesquisa a Tabela 2 sintetiza alguns aspectos relacionados ao perfil de cada estabelecimento. À pedido dos varejistas, o atacadista não foi informado sobre quais empresas participaram da pesquisa.

\subsection{Vantagens e desvantagens das marcas próprias na perspectiva dos clientes varejistas}

Semelhante ao apresentado no item 2.2, os pequenos e médios varejistas entrevistados vislumbram parcialmente as principais vantagens das marcas próprias que também são mencionadas por varejistas de grande porte. Contudo, é preciso ressaltar que no caso dos varejistas pesquisados, o desenvolvimento das marcas não é iniciativa deles, mas do atacadista distribuidor. Além disso, apenas os clientes varejistas associados à rede do atacadista se beneficiam das principais vantagens, pois os varejistas independentes possuem restrições quanto aos vínculos da marca com as lojas. A princípio, observou-se que os clientes varejistas adotam marcas próprias sem definir com antecedência os objetivos a serem alcançados (LAAKSONEN; REYNOLDS, 1994), uma vez que eles pensam a competitividade da marca própria com base em diferentes vantagens. 
Segundo os entrevistados, em condições estáveis de preço, as marcas próprias proporcionam margens de lucro maiores devido ao reduzido custo de aquisição, tornando possível a redução do preço de venda do produto/marca para o consumidor final. Segundo os varejistas, os produtos de marcas próprias - principalmente os produtos de higiene, beleza e limpeza - possibilitam margens de lucro de até 35\% em relação ao custo de compra. Como exceções, alguns produtos de higiene, limpeza e embalagens descartáveis chegam a proporcionar até 50\% de lucratividade, enquanto os mesmos produtos de marcas de fabricantes possibilitam margens de lucro em torno de $20 \%$ a $25 \%$. Em geral, o preço de venda é, em média, 10\% mais baixo do que as marcas de fabricantes líderes.

Apesar de os produtos alimentícios de marcas próprias estarem presentes em maior quantidade nos estabelecimentos, eles possuem margens de lucro menores, com variação de 5\% a 10\% em relação ao custo de compra. Assim, a lucratividade sobre esses itens advém do volume comercializado. Os clientes varejistas ressaltaram que o giro dos produtos alimentícios de marcas próprias na loja depende da variedade de itens sobre os quais a mesma marca está presente. Consequentemente, a lucratividade sobre esses produtos/marcas também depende da variedade ou mix de produtos ofertados na loja. $\mathrm{Na}$ visão dos clientes varejistas, o consumidor fica mais confortável quando observa na gôndola que uma mesma marca está presente em vários produtos alimentícios (percepção de amplitude da marca). Em geral, eles destacaram que esse aspecto é mais comum para produtos alimentícios.

As vantagens que incidem sobre custo de aquisição, margem de lucro e preço de venda têm importantes implicações competitivas para os clientes varejistas. Segundo os gerentes/proprietários, suas lojas se tornam mais atraentes para os consumidores, pois os estabelecimentos concorrentes não conseguem praticar preços equivalentes comercializando produtos/marcas que oferecem atributos de compra semelhantes às

Tabela 2. Caracterização do perfil dos estabelecimentos varejistas entrevistados.

\begin{tabular}{|c|c|c|c|c|c|c|c|c|c|}
\hline \multicolumn{10}{|c|}{ Caracterização do perfil dos estabelecimentos varejistas } \\
\hline $\mathrm{N}^{\circ}$ & $\begin{array}{l}\text { Situação do } \\
\text { varejista }\end{array}$ & UF & $\begin{array}{l}\text { Cargo do } \\
\text { respondente }\end{array}$ & $\begin{array}{c}\text { Tempo de } \\
\text { experiência } \\
\text { em varejo } \\
\text { (anos) }\end{array}$ & $\begin{array}{l}\text { No de } \\
\text { check- } \\
\text { outs na } \\
\text { loja }\end{array}$ & $\begin{array}{l}\text { Tamanho } \\
\text { médio da } \\
\text { loja }\left(\mathrm{m}^{2}\right)\end{array}$ & $\begin{array}{l}\mathrm{N}^{0} \text { médio } \\
\text { de itens } \\
\text { ativos na } \\
\text { loja } \\
(\times 1.000)\end{array}$ & $\begin{array}{l}\mathrm{N}^{\circ} \text { de } \\
\text { itens de } \\
\text { marca } \\
\text { própria }\end{array}$ & $\begin{array}{l}\text { Formato (designação) } \\
\text { de varejo }\end{array}$ \\
\hline 1 & Independente & SP & $\begin{array}{l}\text { Gestor de } \\
\text { negócios }\end{array}$ & 20 & 15 & 2.500 & 12 & 10 & $\begin{array}{l}\text { Supermercado convencional } \\
\text { (médio varejo) }\end{array}$ \\
\hline 2 & Independente & SP & $\begin{array}{c}\text { Gerente de } \\
\text { loja }\end{array}$ & 20 & 20 & 2.600 & 12 & 80 & $\begin{array}{c}\text { Supermercado convencional } \\
\text { (médio varejo) }\end{array}$ \\
\hline 3 & Independente & SP & $\begin{array}{l}\text { Gerente/ } \\
\text { Proprietário }\end{array}$ & 20 & 3 & 0.800 & 5 & 2 & $\begin{array}{l}\text { Supermercado compacto } \\
\text { (pequeno varejo) }\end{array}$ \\
\hline 4 & Independente & $\mathrm{SP}$ & $\begin{array}{c}\text { Gerente/ } \\
\text { Proprietário } \\
\end{array}$ & 46 & 10 & 1.100 & 15 & 2 & $\begin{array}{l}\text { Supermercado convencional } \\
\text { (médio varejo) }\end{array}$ \\
\hline 5 & Independente & MG & $\begin{array}{c}\text { Gerente de } \\
\text { compras }\end{array}$ & 10 & 20 & 2.500 & 15 & 40 & $\begin{array}{l}\text { Supermercado convencional } \\
\text { (médio varejo) }\end{array}$ \\
\hline 6 & Independente & MG & $\begin{array}{c}\text { Gerente/ } \\
\text { Proprietário }\end{array}$ & 7 & 2 & 0.250 & 0,8 & 8 & Minimercado (pequeno varejo) \\
\hline 7 & Independente & MG & $\begin{array}{l}\text { Gerente/ } \\
\text { Proprietário }\end{array}$ & 13 & 1 & 0.100 & 0,3 & 3 & Minimercado (pequeno varejo) \\
\hline 8 & $\begin{array}{l}\text { Associado à } \\
\text { rede }\end{array}$ & SP & $\begin{array}{l}\text { Gerente } \\
\text { comercial }\end{array}$ & 20 & 6 & 0.700 & 7 & 80 & $\begin{array}{l}\text { Supermercado compacto } \\
\text { (pequeno varejo) }\end{array}$ \\
\hline 9 & $\begin{array}{l}\text { Associado à } \\
\text { rede }\end{array}$ & SP & $\begin{array}{c}\text { Gerente/ } \\
\text { Proprietário }\end{array}$ & 15 & 9 & 1.530 & 21 & 25 & $\begin{array}{l}\text { Supermercado convencional } \\
\text { (médio varejo) }\end{array}$ \\
\hline 10 & $\begin{array}{l}\text { Associado à } \\
\text { rede }\end{array}$ & SP & $\begin{array}{c}\text { Gerente/ } \\
\text { Proprietário }\end{array}$ & 15 & 4 & 0.700 & 7 & 100 & $\begin{array}{l}\text { Supermercado compacto } \\
\text { (pequeno varejo) }\end{array}$ \\
\hline 11 & $\begin{array}{l}\text { Associado à } \\
\text { rede }\end{array}$ & SP & $\begin{array}{c}\text { Gerente/ } \\
\text { Proprietário }\end{array}$ & 20 & 5 & 0.800 & 16 & 30 & $\begin{array}{l}\text { Supermercado compacto } \\
\text { (pequeno varejo) }\end{array}$ \\
\hline 12 & $\begin{array}{l}\text { Associado à } \\
\text { rede }\end{array}$ & MG & $\begin{array}{c}\text { Gerente de } \\
\text { compras }\end{array}$ & 2 & 4 & 0.500 & 5 & 50 & $\begin{array}{l}\text { Supermercado compacto } \\
\text { (pequeno varejo) }\end{array}$ \\
\hline 13 & $\begin{array}{l}\text { Associado à } \\
\text { rede }\end{array}$ & MG & $\begin{array}{c}\text { Gerente/ } \\
\text { Proprietário }\end{array}$ & 13 & 4 & 0.420 & 6 & 80 & $\begin{array}{l}\text { Supermercado compacto } \\
\text { (pequeno varejo) }\end{array}$ \\
\hline 14 & $\begin{array}{l}\text { Associado à } \\
\text { rede }\end{array}$ & MG & $\begin{array}{l}\text { Gerente de } \\
\text { compras }\end{array}$ & 8 & 6 & 0.600 & 13 & $\begin{array}{c}\text { não } \\
\text { respondeu }\end{array}$ & $\begin{array}{l}\text { Transição de supermercado } \\
\text { compacto para convencional }\end{array}$ \\
\hline 15 & $\begin{array}{l}\text { Associado à } \\
\text { rede }\end{array}$ & MG & $\begin{array}{c}\text { Gerente/ } \\
\text { Proprietário }\end{array}$ & 12 & 3 & 0.350 & 8 & 20 & $\begin{array}{l}\text { Supermercado compacto } \\
\text { (pequeno varejo) }\end{array}$ \\
\hline
\end{tabular}

Fonte: elaborado pelos autores a partir de dados da pesquisa. 
marcas próprias. A lucratividade é o que sustenta a sobrevivência dos estabelecimentos, pois possibilita a realização de investimentos na estrutura, no mix de produtos e, principalmente, em serviços na loja.

A exclusividade de comercialização da marca própria foi outra importante vantagem competitiva mencionada por alguns clientes varejistas. Para eles, o fato de esses produtos/marcas serem encontrados apenas em seu estabelecimento faz com que o consumidor não tenha em outro ponto de venda próximo um produto/marca idêntico que possa ser alvo de comparação. Assim, na medida em que o consumidor se habitua à compra da marca própria, ele a relaciona diretamente ao estabelecimento varejista. Isso pode ser observado a partir do relato de um proprietário varejista associado à rede do atacadista:

0 cliente não tem outro lugar pra comprar, por exemplo, você pode colocar o preço, aumentar a margem [...] porque não tem o comparativo, ele só vai ter a marca própria [...] se ele habituar a comprar papel higiênico dessa marca, por exemplo, ele não vai achar em outro lugar, [...] vai ter que vir aqui.

Segundo os varejistas independentes, a exclusividade da marca própria ocorre no âmbito da diferenciação dos atributos do produto/marca, quando o consumidor atribui maior percepção de valor à marca própria em relação às marcas de fabricantes, por exemplo, apreciando o sabor diferenciado de um alimento. Caso contrário não há exclusividade de ponto de venda em relação às marcas próprias, uma vez que essas marcas não possuem relação direta com a imagem das lojas. A ausência dessa exclusividade faz com que os clientes varejistas independentes tratem a marca própria como qualquer outro produto/marca de fabricante, visualizando apenas as vantagens relacionadas ao custo, margens e preço de venda, além de outras relacionadas aos serviços de entrega e abastecimento do atacadista distribuidor. Nesse sentido, nota-se que esses clientes varejistas utilizam as marcas próprias como alternativa eficiente e econômica de reposição de gôndola.

Da mesma forma que as marcas próprias vinculadas à rede organizada pelo atacadista não são interessantes para os clientes varejistas independentes, os varejistas associados à rede também pouco se interessam pelas marcas próprias que não possuem o mesmo nome de sua loja. Esses clientes varejistas só comercializam outras marcas do atacadista distribuidor quando essas marcas possuem oferta padronizada na rede, ou seja, quando os varejistas associados à rede de determinada região definem atividades promocionais (jornal de ofertas, por exemplo) que incluem essas marcas. No relato de um proprietário varejista associado à rede, observa-se o seu descontentamento com a possibilidade de outros varejistas comercializarem marcas próprias do atacadista:
[...] a principal diferença que eu vejo na marca própria é que justamente outros não filiados à rede do atacadista não podiam ter essas marcas, mas um concorrente meu que não era associado à rede tinha [...] quando qualquer um compra essas marcas o diferencial acaba. Por isso eu dou preferência à marca da rede, porque é a marca da minha loja e que só tem aqui.

A preferência pela marca própria da rede ocorre porque os clientes varejistas buscam outras importantes vantagens como: o vínculo da marca própria ao nome e imagem da loja (e da rede) como forma de diferenciação do estabelecimento e fidelização dos clientes. Para os gerentes/proprietários entrevistados, esse vínculo fortalece o nome da loja na mente dos clientes, auxilia nas atividades de comunicação no bairro e estimula a experimentação das marcas próprias por parte dos consumidores que confiam na loja e no proprietário do estabelecimento. Conforme mencionaram Keller (2001) e Aaker (1998, 2001), esse vínculo ajuda na proeminência da marca, assim como na conscientização dos consumidores sobre ela. No relato de dois proprietários varejistas associados à rede de varejo é possível observar a percepção dessas vantagens:

[...] o pessoal liga muito o nome da rede, o nome da loja com o nome da marca. A marca que não tem o nome da rede é marca própria porque é do atacadista; eu sei disso porque eu compro deles, mas o consumidor não sabe, então ele não liga essa marca à marca própria da rede.

[...] com a marca própria você leva o nome da sua empresa, você faz mais a sua propaganda [...] a propaganda da sua loja, ao invés de você fazer propaganda de outras firmas, você faz propaganda da sua empresa.

A possibilidade de vincular a marca própria à imagem da loja é uma vantagem restrita aos clientes varejistas associados à rede. 0 s varejistas independentes não desfrutam dessa vantagem que, segundo eles, é ambígua, pois traz benefícios na mesma proporção em que produz riscos de associações danosas à imagem das lojas. Problemas ocorridos com as marcas próprias, como queda na qualidade dos produtos, gerenciamento inadequado das categorias, deficiência no atendimento aos clientes, podem afetar a imagem da loja (SOUZA; NEMER, 1993). No mesmo sentido, os clientes varejistas associados à rede de varejo demonstraram preocupação com a aceitação das marcas próprias pelos consumidores. Segundo eles, isso depende do desempenho de todos os produtos que levam a mesma marca, pois o consumidor pode criar associações favoráveis, assim como desfavoráveis (KELLER, 2001) com base no desempenho de todos os produtos de marcas próprias da rede. Esse aspecto sinaliza a primeira dificuldade ou risco que as marcas próprias podem proporcionar. 
Ao serem questionados sobre as desvantagens das marcas próprias, os clientes varejistas não relataram desvantagens concretas, apenas dificuldades inerentes ao processo de comercialização. Um ponto interessante é que a obtenção da lucratividade sobre produtos alimentícios de marcas próprias necessita da aquisição de um mix de produtos que gere nos consumidores a percepção de segurança com base na amplitude de produtos de marcas próprias disponíveis. Todavia, a aquisição e manutenção desse mix é arriscada para o cliente varejista, que possui o receio de que algum produto possa encalhar na gôndola, ocupando espaço e reduzindo a lucratividade originalmente planejada. Além disso, um mix amplo também reforça o risco relacionado às possíveis falhas de qualidade de produtos (SULLIVAN; ADCOCK, 2002) que utilizam a marca da rede.
Algumas dificuldades apontadas pelos clientes varejistas associados à rede organizada pelo atacadista estão diretamente relacionadas às desvantagens da própria associação à rede. Entre essas desvantagens está a oscilação dos preços dos produtos de marcas próprias, que força os clientes varejistas a estabelecerem em curtos períodos preços diferentes para o mesmo produto/marca. A oscilação dos preços prejudica a lucratividade, o planejamento de abastecimento da loja e a imagem da marca junto ao consumidor; comparativamente, esse fato não é apontado por varejistas de grande porte. Na perspectiva dos clientes varejistas, isso ocorre porque 0 atacadista distribuidor não possui muita experiência sobre o planejamento/ previsão de demanda para os seus produtos/marcas.

Outra desvantagem apontada pelos clientes varejistas é que a associação à rede do atacadista pressiona indiretamente a introdução de marcas

Quadro 1. Síntese das vantagens das marcas próprias para os agentes distribuidores.

\begin{tabular}{|c|c|c|c|c|}
\hline \multicolumn{5}{|c|}{ Sintese comparativa das principais vantagens das marcas próprias } \\
\hline Vantagens & $\begin{array}{c}\text { Varejistas } \\
\text { (grande porte) }\end{array}$ & $\begin{array}{l}\text { Atacadistas } \\
\text { distribuidores }\end{array}$ & $\begin{array}{c}\text { Clientes } \\
\text { varejistas } \\
\text { associados à rede }\end{array}$ & $\begin{array}{l}\text { Clientes } \\
\text { varejistas } \\
\text { independentes }\end{array}$ \\
\hline Margens de lucro mais elevadas & $x$ & $X$ & $\mathrm{x}$ & $\mathrm{x}$ \\
\hline Melhor administração do portfólio de produtos & $\mathrm{X}$ & $\mathrm{x}$ & & \\
\hline Maior independência na fixação do preço final & $\mathrm{x}$ & & & \\
\hline Maior competitividade frente à concorrência & $\mathrm{x}$ & & $\mathrm{x}$ & \\
\hline $\begin{array}{l}\text { Ausência de custos e riscos envolvidos no desenvolvimento de } \\
\text { instalações e processos produtivos, já que esses pertencem ao } \\
\text { contratado (fabricante) }\end{array}$ & $\mathrm{x}$ & & $\mathrm{x}$ & $x$ \\
\hline $\begin{array}{l}\text { Facilidade de manutenção dos padrões de qualidade pela } \\
\text { negociação com fornecedores diferentes, selecionando os que } \\
\text { atendem as especificações }\end{array}$ & & $\mathrm{x}$ & & \\
\hline $\begin{array}{l}\text { Capacidade de controlar os níveis de estoque por cláusulas de } \\
\text { contrato que determinam o volume de produção do fabricante }\end{array}$ & & $\mathrm{X}$ & & \\
\hline Maior controle sobre prazos e formas de entrega & & $x$ & & \\
\hline $\begin{array}{l}\text { Independência relativa em relação aos fornecedores, além de } \\
\text { aumento do poder de negociação no canal }\end{array}$ & $\mathrm{X}$ & & & \\
\hline $\begin{array}{l}\text { Redução da dependência dos produtos de marcas tradicionais (para } \\
\text { varejo e atacado) }\end{array}$ & $\mathrm{x}$ & $\mathrm{x}$ & & \\
\hline Maior controle sobre comunicação e promoções & $\mathrm{x}$ & $x$ & & \\
\hline Atendimento às necessidades de segmentos específicos de clientes & $\mathrm{x}$ & $\mathrm{x}$ & & \\
\hline Exclusividade da marca pode representar vantagem competitiva & $\mathrm{x}$ & $\mathrm{X}$ & $\mathrm{x}$ & \\
\hline $\begin{array}{l}\text { Vinculação da marca ao nome e imagem da loja (e da rede) } \\
\text { estimula a fidelidade/lealdade à loja e, consequentemente, à marca }\end{array}$ & $\mathrm{X}$ & & $\mathrm{x}$ & \\
\hline Maior visibilidade do estabelecimento no bairro de atuação & & & $\mathrm{x}$ & \\
\hline $\begin{array}{l}\text { Marcas próprias mantêm o nome do varejista na casa do } \\
\text { consumidor }\end{array}$ & $\mathrm{X}$ & & $\mathrm{x}$ & \\
\hline Fortalecimento da imagem do distribuidor & $x$ & $x$ & & \\
\hline Construção de relacionamentos de confiança e credibilidade & $\mathrm{x}$ & $x$ & & \\
\hline $\begin{array}{l}\text { Propiciam redução de competição por preços na esfera do varejista, } \\
\text { principalmente porque a marca não está disponivel em outros } \\
\text { estabelecimentos }\end{array}$ & $\mathrm{x}$ & & & \\
\hline Possibilita a inovação de produtos no mercado & $x$ & $x$ & & \\
\hline $\begin{array}{l}\text { Maior identificação do pessoal de vendas com os produtos de } \\
\text { marcas próprias devido ao incentivo na comissão de vendas (para } \\
\text { os atacadistas) }\end{array}$ & & $\mathrm{x}$ & & \\
\hline
\end{tabular}

Fonte: elaborado pelos autores a partir do referencial teórico e dos resultados da pesquisa. 
Quadro 2. Síntese das desvantagens/dificuldades ou riscos das marcas próprias para os agentes distribuidores.

\begin{tabular}{|c|c|c|c|c|}
\hline \multicolumn{5}{|c|}{ Sintese comparativa das principais desvantagens/dificuldades ou riscos das marcas próprias } \\
\hline Desvantagens/dificuldades ou riscos & $\begin{array}{c}\text { Varejistas } \\
\text { (grande porte) }\end{array}$ & $\begin{array}{l}\text { Atacadistas } \\
\text { distribuidores }\end{array}$ & $\begin{array}{l}\text { Clientes varejistas } \\
\text { associados à rede }\end{array}$ & $\begin{array}{l}\text { Clientes } \\
\text { varejistas } \\
\text { independentes }\end{array}$ \\
\hline Pode gerar estoques elevados & $\mathrm{X}$ & & & \\
\hline Limita alternativas estratégicas de fornecimento & $\mathrm{x}$ & & & \\
\hline Despesas adicionais podem reduzir rentabilidade & $\mathrm{X}$ & $\mathrm{x}$ & & \\
\hline $\begin{array}{l}\text { Necessidade de esforços complementares de comunicação } \\
\text { (principalmente os atacadistas) }\end{array}$ & & $\mathrm{x}$ & & \\
\hline $\begin{array}{l}\text { Falta de domínio no ponto de venda ocasionada pela falta de } \\
\text { contato com o consumidor final dos produtos de marcas próprias } \\
\text { (para os atacadistas) }\end{array}$ & & $\mathrm{x}$ & & \\
\hline $\begin{array}{l}\text { Dificuldades em trabalhar com categorias de produto que possuam } \\
\text { marcas de fabricante com forte investimento em mídia }\end{array}$ & & $\mathrm{x}$ & $x$ & \\
\hline $\begin{array}{l}\text { Pode condicionar excessivamente o conteúdo da comunicação do } \\
\text { distribuidor }\end{array}$ & $\mathrm{x}$ & $\mathrm{x}$ & $\mathrm{x}$ & \\
\hline $\begin{array}{l}\text { Exige estrutura própria de pesquisa, desenvolvimento e controle } \\
\text { de qualidade }\end{array}$ & $\mathrm{x}$ & & & \\
\hline Riscos assumidos pelo distribuidor & $\mathrm{X}$ & $\mathrm{x}$ & & \\
\hline $\begin{array}{l}\text { Problemas individuais podem comprometer a imagem global da } \\
\text { marca e do distribuidor }\end{array}$ & $x$ & $\mathrm{x}$ & $\mathrm{x}$ & \\
\hline $\begin{array}{l}\text { Limitações na disponibilização da prestação de serviços, quando } \\
\text { esse for aspecto crítico }\end{array}$ & $\mathrm{x}$ & $\mathrm{x}$ & & \\
\hline $\begin{array}{l}\text { Risco de romper o acordo de fornecimento de marca própria pode } \\
\text { causar problemas para manter o nível de qualidade dos produtos e } \\
\text { a garantia de abastecimento }\end{array}$ & $x$ & $x$ & & \\
\hline $\begin{array}{l}\text { Quando a oferta de marca própria excede certo percentual da linha de } \\
\text { produtos ou das vendas a variedade do distribuidor pode ser percebida } \\
\text { como limitada ou monótona }\end{array}$ & $x$ & & & \\
\hline $\begin{array}{l}\text { Conquista de prestígio somente num segundo estágio (longo } \\
\text { prazo) }\end{array}$ & $x$ & $X$ & & \\
\hline $\begin{array}{l}\text { Oscilação dos preços prejudica o planejamento, a imagem e a } \\
\text { lucratividade da loja }\end{array}$ & & & $x$ & \\
\hline $\begin{array}{l}\text { A associação à rede pode pressionar indiretamente a introdução de } \\
\text { produtos indesejados }\end{array}$ & & & $x$ & \\
\hline $\begin{array}{l}\text { Padronização excessiva das ofertas e ações de comunicação pode } \\
\text { reduzir a lucratividade }\end{array}$ & & & $x$ & \\
\hline $\begin{array}{l}\text { Risco em manter um mix amplo de produtos, pois podem } \\
\text { aumentar os custos de estoques e reduzir-se a lucratividade }\end{array}$ & & & $x$ & \\
\hline $\begin{array}{l}\text { Riscos associados ao insucesso de um produto pode comprometer } \\
\text { a imagem da marca e do estabelecimento }\end{array}$ & & & $x$ & \\
\hline $\begin{array}{l}\text { Dificuldade na comercialização de marcas próprias quando existem } \\
\text { marcas regionais e/ou locais valorizadas pelos consumidores e com } \\
\text { forte investimento na mídia local }\end{array}$ & & & $x$ & \\
\hline $\begin{array}{l}\text { Despesas adicionais para suprir deficiências de comercialização } \\
\text { podem reduzir a rentabilidade geral das marcas próprias }\end{array}$ & & & $x$ & \\
\hline
\end{tabular}

Fonte: elaborado pelos autores a partir do referencial teórico e dos resultados da pesquisa.

próprias nas lojas. Segundo alguns gerentes/ proprietários, essa desvantagem é reflexo da padronização das atividades de comunicação da rede, principalmente do jornal de ofertas - sua composição, muitas vezes, obriga o varejista a disponibilizar espaço na gôndola para determinado produto não aceito em outras oportunidades pelos consumidores ou que a loja já dispõe mas de outra marca. Assim, o varejista se ajusta ao jornal de ofertas mas, na prática, não consegue fazer o produto girar na loja. Destaca-se que os varejistas de grande porte são autônomos em relação às atividades de comunicação de suas marcas.
Os gerentes/proprietários associados à rede também destacaram a dificuldade na comercialização de determinados produtos de marcas próprias quando existem marcas regionais e/ou locais valorizadas pelos consumidores. Como exemplo, alguns produtos alimentícios como arroz, feijão, café e macarrão, que constantemente figuram no jornal de ofertas da rede, possuem aceitação diversificada em cada região ou cidade. Os clientes varejistas, principalmente de pequeno porte, ressaltaram que ainda é grande a dependência de marcas regionais/locais e das marcas de fabricantes líderes de mercado, pois o perfil dos consumidores dessas lojas de bairro requer a presença 
dessas marcas nas gôndolas. Além disso, é comum essas marcas receberem forte investimento na mídia local, o que estimula a procura dos consumidores.

Comparativamente, as dificuldades de comercialização de marcas próprias para os clientes varejistas de um atacadista distribuidor são proporcionalmente menores em relação às dificuldades destacadas por varejistas de grande porte e por atacadistas em geral. Nesse sentido, os investimentos em design e teste de produtos, embalagens, estoques, displays promocionais e propaganda, além da responsabilidade sobre o desenvolvimento do produto/ marca e a coordenação da fonte de suprimento $(\mathrm{HOCH}$; BANERJI, 1993; McGOLDRICK, 2005) continuam a cargo do atacadista distribuidor que formula a estratégia. 0 cliente varejista é apenas um elo dessa estratégia. Isso significa que ele assume menos riscos, embora não menos impactantes ao seu negócio e à estratégia.

Nota-se que algumas dificuldades e riscos apontados pelos clientes varejistas são inerentes à comercialização de todo tipo de produto/marca. Destaca-se que os clientes varejistas independentes não relataram dificuldades e ou riscos na comercialização de marcas próprias. A seguir, os Quadros 1 e 2 sintetizam comparativamente as principais vantagens, desvantagens/dificuldades e/ou riscos das marcas próprias na perspectiva de varejistas de grande porte, atacadistas distribuidores e seus clientes varejistas. Os X marcados nos Quadros representam o que os diferentes agentes e perfis indicaram como vantagem e desvantagem.

\section{Conclusões e sugestões de pesquisa}

Conforme proposto, este artigo identificou e discutiu as principais vantagens e desvantagens/ dificuldades ou riscos que as marcas próprias proporcionam aos pequenos e médios varejistas. Constatou-se que muitas vantagens e desvantagens relacionadas pela literatura com base no setor varejista de grande porte também se assemelham àquelas apontadas pelos pequenos e médios varejistas estudados. Assim, algumas vantagens como: obter maior lucratividade, exclusividade da marca (para alguns varejistas), fidelizar consumidores, transmitir a imagem da empresa e a identidade da marca própria; e a desvantagem relacionada aos riscos associados a um possível insucesso da marca própria são percepções compartilhadas entre varejistas de pequeno, médio e grande porte e atacadistas.

Contudo, verificou-se que apenas os clientes varejistas associados à rede do atacadista se beneficiam das principais vantagens das marcas próprias, uma vez que os varejistas independentes têm restrições quanto aos vínculos da marca às lojas. Assim, esses clientes veem como principal vantagem a obtenção de margens de lucro mais elevadas. Isso explica o baixo nível de comprometimento desses clientes com as marcas próprias, uma vez que são tratadas como opções de reposição a marcas de outros fabricantes.

Ressalta-se que as declarações dos pequenos e médios varejistas entrevistados são exclusivamente em referência às marcas próprias desenvolvidas pelo atacadista distribuidor que colaborou com a pesquisa. Dessa forma, as declarações e considerações contidas neste artigo não podem ser generalizadas para a atuação desse atacadista distribuidor em relação à comercialização de outras mercadorias, ou seja, para produtos/marcas de outros fabricantes. Cuidado adicional deve ser tomado em quaisquer tipos de comparações, para que não ocorram generalizações indevidas sobre a atuação do atacadista junto aos seus clientes varejistas. Destaca-se ainda que as discussões sobre as vantagens e desvantagens das marcas próprias precisam ser tratadas com as restrições inerentes ao perfil do varejista (ou situação de associação em rede), para que as diferenças entre as perspectivas desses clientes sejam consideradas individualmente, mesmo que as lojas possuam o mesmo porte.

Este artigo é recorte de uma pesquisa mais ampla, que possui diversas vertentes e detalhamentos que, por razões de espaço e foco, não foram apresentados e discutidos. Para pesquisas futuras, sugere-se que sejam realizados outros estudos qualitativos que abordem casos múltiplos de varejistas com o mesmo perfil de atuação, para que a construção de conjecturas sobre a estratégia de marcas próprias do atacado distribuidor estabeleça um padrão coerente de aplicação. Além disso, há eminente necessidade de que novos estudos sejam dirigidos a outras regiões do país, principalmente para as que apresentam contextos diferenciados de consumo de produtos de marcas próprias. Sugere-se, ainda, que para complementar este estudo seja realizada uma análise comparativa das vantagens e desvantagens das marcas próprias sob a óptica do varejo supermercadista, do atacado distribuidor e da indústria fornecedora (não contemplada neste artigo). Esse tipo de estudo poderia promover uma interpretação ainda mais objetiva dos aspectos que favorecem e/ou restringem a adoção de marcas próprias.

\section{Referências}

AAKER, D. A. Marcas: brand equity: gerenciando o valor da marca. 2. ed. São Paulo: Negócio, 1998. 309 p.

AAKER, D. A. Criando e administrando marcas de sucesso. 3. ed. São Paulo: Futura, 2001.

ASSOCIAÇÃO BRASILEIRA DE SUPERMERCADOS - ABRAS. Comitês - Pesquisa Marcas Próprias: análise anual mostra estágio das marcas próprias. Disponível em: <http://www.abrasnet.com.br/comites/marcas-proprias/ pesquisa-marcas-proprias/> Acesso em: 15 jul. 2010.

ASSOCIAÇÃO BRASILEIRA DE SUPERMERCADOS - ABRAS. Economia e Pesquisa - Pesquisas Sazonais/Marcas 
Próprias. Disponível em: <http://www.abrasnet.com. $\mathrm{br} /$ economia-e-pesquisa/pesquisas-sazonais/marcasproprias/>. Acesso em: 27 jan. 2011.

AlLAWADI, K. L.; KELLER, K. L. Understanding retail branding: conceptual insights and research priorities. Journal of Retailing, v. 80, p. 331-342, 2004.

ALCÂNTARA, R. L. C. A gestão estratégica dos canais de distribuição: um exame da evolução e do atual estágio do relacionamento entre o atacado de entrega e a indústria. 1997. 194 f. Tese (Doutorado em Administração)Fundação Getúlio Vargas, São Paulo, 1997.

BALTAS, G. A combined segmentation and demand model for store brands. European Journal of Marketing, v. 37, n. 10, p. 1499-1513, 2003. http://dx.doi. org/10.1108/03090560310487211

BARDIN, L. Análise de conteúdo. 3. ed. Lisboa: Edições 70, 2004. 223 p.

BATRA, R.; SINHA, 1. Consumer-level factors moderating the success of private label brands. Journal of Retailing, v. 76, n. 2, p. 175-191, 2000. http://dx.doi.org/10.1016/ S0022-4359(00)00027-0

BAUER, M. W.; GASKELL, G. Pesquisa qualitativa com texto, imagem e som: manual prático. Petrópolis: Vozes, 2002.

BELL, D.; CUTHBERTSON, R.; KOSKINEN, S. Customer loyalty and private labels products: pesquisa realizada para a KPMG: Canadá, 5/1/2005. Disponível em: <http://www. kpmg.ca>. Acesso em: 4 out. 2005.

BERKOWITZ, E. N. et al. Marketing. 6. ed. Rio de Janeiro: LTC, 2003. v. 2, 454 p.

BOWERSOX, D. J.; COOPER, M. B. Strategic marketing channel management. New York: McGraw-Hill, 1992.

BURT, S. The strategic role of retail brands in British grocery retailing. European Journal of Marketing, v. 34, n. 8, p. 875897, 2000.http://dx.doi.org/10.1108/03090560010331351

CHURCHILL JUNIOR, G. A.; PETER, J. P. Marketing: criando valor para o cliente. 2. ed. São Paulo: Saraiva, 2000.

CONN, C. Innovation in private-label branding. Design Management Review, v. 16, n. 2, p. 55-72, 2005. http:// dx.doi.org/10.1111/j.1948-7169.2005.tb00194.x

CORSTJENS, M.; LAL, R. Building store loyalty through store brands. Journal of Marketing Research, v. 37, n. 3, p. 281 291, 2000. http://dx.doi.org/10.1509/jmkr.37.3.281.18781

COUGHLAN, A. T. et al. Canais de marketing e distribuição. 6. ed. Porto Alegre: Bookman, 2002. 461 p.

DATTA, P. The determinants of brand loyalty. Journal of American Academy of Business, v. 3, n. 1-2, p. 138, 2003.

DAVIES, G.; BRITO, E. Price and quality competition between brands and own brands: a value systems perspective. European Journal of Marketing, v. 38, n. 1-2, p. 3055, 2004. http://dx.doi.org/10.1108/03090560410511113

DENZIN, N. K.; LINCOLN, Y. S. Introduction: entering the field of qualitative research. In: DENZIN, N. K.; LINCOLN, Y. S. (Org.). The Landscape of Qualitative Research. Thousand Oaks: Sage Publications, 1998. p. 1-34.

DHAR, S. K.; HOCH, S. J. Why store brand penetration varies by retailer. Marketing Science, v. 16, n. 3, p. 208227, 1997. http://dx.doi.org/10.1287/mksc.16.3.208

DHAR, S. K. et al. Effective category management depends on the role of the category. Journal of Retailing, v. 77, p. 165-184, 2001. http://dx.doi.org/10.1016/S00224359(01)00045-8

EL01, C. Ranking 2009/análise: 2008 melhor que 2007. Revista Distribuição, ano 17, n. 196, p. 126-156, maio 2009.
ELOl, C. Ranking 2011/canais de vendas: Sortimento mais atrativo. Revista Distribuição, ano 19, n. 220, p. 132138, maio 2011.

GARRETSON, J. A. et al. Antecedents of private label attitude and national brand promotion attitude: similarities and differences. Journal of Retailing, v. 78, p. 91-99, 2002. http://dx.doi.org/10.1016/S0022-4359(02)00071-4

GÓMEZ, M.; BENITO, N. R. Manufacturer's characteristics that determine the choice of producing store brands. European Journal of Marketing, v. 42, n. 1-2, p. 154177, 2008.

GÓMEZ, M.; RUBIO, N. Shelf management of store brands: analysis of manufacturers' perceptions. International Journal of Retail \&t Distribution Management, v. 36, n. 1, p. 50-70, 2008.

HALSTEAD, D.; WARD, C. B. Assessing the vulnerability of private label brands. Journal of Product \& Brand Management, v. 4, n. 3, p. 38-48, 1995. http://dx.doi. org/10.1108/10610429510097636

HILÁRIO, W. Ranking 2009: o melhor desempenho dos últimos 13 anos. Revista SuperHiper, ano 35, n. 396, p. 28-51, abr. 2009.

HILÁRIO, W. Ranking 2010: 500 do ranking crescem mais que o setor. Revista SuperHiper, ano 36, n. 407, p. 4852, abr. 2010

$\mathrm{HOCH}, \mathrm{S}$. J. How should national brands think about private labels? Sloan Management Review, v. 37, n. 2, p. 89102, 1996

HOCH, S. J.; BANERJl, S. When do private labels succeed? Sloan Management Review, v. 34, n. 4, p. 57-67, 1993.

HUANG, Y.; HUDDLESTON, P. Retailer premium ownbrands: creating customer loyalty through own-brand products advantage. International Journal of Retail and Distribution Management, v. 37, n. 11, p. 975-992, 2009. http://dx.doi.org/10.1108/09590550910999389

KELLER, K. L. Building customer-based brand equity. Marketing Management, v. 10, n. 2, p. 14-19, 2001.

KELLER, K. L.; MACHADO, M. Gestão estratégica de marcas. São Paulo: Pearson Prentice Hall, 2006. 289 p.

KOTLER, P.; KELLER, K. L. Administração de marketing. 12. ed. São Paulo: Pearson Prentice Hall, 2006.

KUMAR, N.; STEENKAMP, J-B. E. M. Estratégia de marcas próprias. São Paulo: M. Books, 2008. 213 p.

LAAKSONEN, H.; REYNOLDS, J. Own brands in food retailing across Europe. The Journal of Brand Management, v. 2, n. 1, p. 37-46, 1994.

LUKIANOCENKO, M. Marca própria: passa a ter maior percepção de valor. Revista SuperHiper, ano 36, n. 414, p. 84-88, nov. 2010.

MASON, J. Mixing methods in a qualitatively driven way. Qualitative Research, v. 6, n. 1, p. 9-25, 2006. http:// dx.doi.org/10.1177/1468794106058866

MAXWELL, J. A. Methods: what will you actually do? In: MAXWELL, J. A. Qualitative Research Design: an interactive approach. Thousand Oaks: Sage Publications, 1996. cap. 5, p. 63-85.

McGOLDRICK, P. J. Varejo. In: BAKER, M. J. et al. Administração de marketing. 5. ed. Rio de Janeiro: Campus (Elsevier), 2005. 603 p. cap. 30.

OLIVEIRA, R. N. A. Marca própria. Rio de Janeiro: Brasport, 2005. 251 p.

OLIVER, C. M. Fornecimento de marcas próprias para supermercados: fatores propulsores e restritivos. In: ÂNGELO, C. F.; SILVEIRA, J. A. G. (Orgs.). Varejo Competitivo. São Paulo: Atlas, 2001. v. 5. 
OUBIÑA, J.; RUBIO, N.; YAGÜE, M. J. Strategic management of store brands: an analysis from the manufacturer's perspective. International Journal of Retail \& Distribution Management, v. 34, n. 10, p. 742-760 2006.

PARENTE, J. Varejo no Brasil: gestão e estratégia. São Paulo: Atlas, 2000. 388 p.

PARKER, P.; KIM, N. National brands versus private labels: an empirical study of competition, advertising and collusion. European Management Journal, v. 15, n. 3, p. 220-235, 1997. http://dx.doi.org/10.1016/S02632373(97)00003-0

PAULA, V. A. F. Estratégia de marcas no varejo de alimentos: concepção e gestão de marcas próprias na lnglaterra e no Brasil. 2008. 224 f. Tese (Doutorado em Engenharia de Produção)-Universidade Federal de São Carlos, São Carlos, 2008.

PEETERS, T. H. et al. Estratégias de marca própria refletida na imagem percebida pelos compradores de super/ hipermercados. Revista Jovens Pesquisadores, ano 3, n. 4, jan./jun. 2006 .

PIATO, E. L. Estratégia de marcas próprias: estudo multicaso no atacado brasileiro. 2006. 257 f. Dissertação (Mestrado em Engenharia de Produção)-Universidade Federal de São Carlos, São Carlos, 2006.

PIATO, E. L.; PAULA, V. A. F.; SILVA, A. L. Gestão de marcas próprias: novas dimensões para indústria atacado e varejo. São Paulo: Atlas, 2011. 192 p.

PUERTA, R. Mercado em expansão: pesquisa marca própria. Revista Distribuição, São Paulo, ano 14, n. 158, p. 38-40, fev. 2006.

RICHARDSON, S. P. Are store brands perceived to be just another brand? Journal of Product \& Brand Management, v. 6, n. 6, p. 388-404, 1997. http://dx.doi. org/10.1108/10610429710190432

RICHARDSON, R. J. et al. Pesquisa social: métodos e técnicas. 3. ed. São Paulo: Atlas, 1999.

SOUZA, M. G.; NEMER, A. Marca Et distribuição: desenvolvendo dominação estratégica e vantagem competitiva no mercado global. São Paulo: Makron Books, 1993. 239 p.

STEINER, R. L. The nature and benefits of national brand/private label competition. Review of Industrial Organization, v. 24, n. 2, p. 105-127, 2004. http:// dx.doi.org/10.1023/B:RE10.0000033351.66025.05
STERN, L. W.; El-ANSARY, A. 1.; COUGHLAN, A. T. Marketing channels. 5. ed. New Jersey: Prentice Hall, 1996. 576 p.

STRAUSS, A. L.; CORBIN, J. Basics of qualitative research: techniques and procedures for developing grounded theory. Thousand Oaks: SAGE Publications, 1998.

SULLIVAN, M.; ADCOCK, D. Retail marketing. London: Thomson, 2002. $350 \mathrm{p}$.

TARZIJÁN, J. Should national brand manufacturers produce private labels? Journal of Modelling in Management, v. 2, n. 1, p. 56-70, 2007. http://dx.doi. org/10.1108/17465660710733059

TAVARES, M. C. A força da marca: como construir e manter marcas fortes. São Paulo: Harbra, 1998. 220 p.

TOILLIER, A. L. Análise do mercado supermercadista de marcas próprias sob a perspectiva do fabricante. 2003. $119 \mathrm{f}$. Dissertação (Mestrado em Administração)-Universidade Federal do Rio Grande do Sul, Porto Alegre, 2003.

VAHIE, A.; PASWAN, A. Private label brand image: its relationship with store image and national brand. International Journal of Retail \& Distribution Management, v. 34, n. 1, p. 67-84, 2006. http://dx.doi. org/10.1108/09590550610642828

VERHOEF, P. C.; NIJSSEN, E. J.;SLOOT, L. M. Strategic reactions of national brand manufacturers towards private labels: an empirical study in the Netherlands. European Journal of Marketing, v. 36, n. 11-12, p. 1309-1326, 2002. http://dx.doi.org/10.1108/03090560210445191

YOKOYAMA, M. H. Análise das estratégias de produção em fornecedores de marcas próprias: estudo multicaso em empresas do setor de alimentos. 2010. 206 f. Dissertação (Mestrado em Engenharia de Produção)-Universidade Federal de São Carlos, São Carlos, 2010.

\section{Agradecimentos}

Os autores agradecem à Fapesp - Fundação de Amparo à Pesquisa do Estado de São Paulo a concessão de uma bolsa de doutorado e uma bolsa de pós-doutoramento (Programa Novas Fronteiras) durante a realização desta pesquisa.

\title{
Analysis of advantages and disadvantages of wholesaler's own brands for retail customers
}

\begin{abstract}
The aim of this paper is to identify and discuss the main advantages and disadvantages of wholesaler's own brands for small and medium retailers. In a qualitative, exploratory study, 15 semi-structured interviews with supermarket retailers were conducted. The results show that the advantages and disadvantages mentioned by the interviewed retailers were similar to those obtained in a literature review, which was mostly based on large retailers and wholesalers. The interviewed retailers also mentioned difficulties inherent to wholesaler brands. It was also found that only retailers associated with the wholesaler benefit from the association between the brand and the store, as independent retailers have restrictions in bonding the brands to their stores. Independent retailers primarily benefit from higher profit margins. The disadvantages and difficulties encountered in offering wholesaler brands are also mentioned by the interviewed retail customers.
\end{abstract}

\section{Keywords}

Own brands. Wholesale distributor. Supermarket retailer. 